\title{
Pelourinho em São Luís: narrativa por meio do design e ativismo sobre memória coletiva no museu Cafua das Mercês
}

\author{
Felipe Pereira Raposo ${ }^{1}$; \\ Daniela Menezes Moreira ${ }^{2}$ \\ Camila Pereira Melo3; \\ Alina Karen Abreu Berrêdo"; \\ Raquel Gomes Noronha5;
}

resumo:

Este artigo apresenta o processo de construção do projeto gráfico vinculado à uma narrativa sobre o Pelourinho, acervo patrimonial em exposição no Museu Cafua das Mercês, na cidade de São Luís. Inspirados por experiências e reflexões acerca de Museus http://lattes.cnpq.br/1884579998550541Afrodigitais no Brasil, graduandos de Design da Universidade Federal do Maranhão seguiram os passos metodológicos orientados pela disciplina Projeto Gráfico I: iniciando com revisão bibliográfica e estudo em grupo de referências teóricas relativas à construção de narrativas étnicas em exposições museológicas; seguida de escuta interativa com equipe técnica do Cafua das Mercês para conhecer a narrativa adotada por este museu; além da experimentação de técnicas criativas como mapa mental, moodboard e storyboard para a elaboração de peças gráficas alinhadas ao conceito de museu como zona de contato, descrito por James Clifford (2016).

palavras-chave:

Museu; projeto gráfico; pelourinho.

Espaço reservado para organização do congresso.

\footnotetext{
${ }^{1}$ http://lattes.cnpq.br/5839296161228226

${ }^{2} \mathrm{http} / / /$ lattes.cnpq.br/1884579998550541

${ }^{3} \mathrm{http}: / /$ lattes.cnpq.br/0127031883652600

${ }^{4} \mathrm{http} / / /$ lattes.cnpq.br/0910163685856671

${ }^{5} \mathrm{http}: / /$ lattes.cnpq.br/4782161324909358
} 


\section{JOP

"O que dizer do rótulo para tecidos que enaltece a reunião entre brancos e negros a partir de uma lei exclamando 'Agora sim!'? Nada mais superficial e hipócrita, típico de uma sociedade que por muito tempo tentou se equilibrar na contradição de querer ser liberal e moderna sendo de fato escravocrata." (REZENDE, 2011. p.37) [Imagem 1].

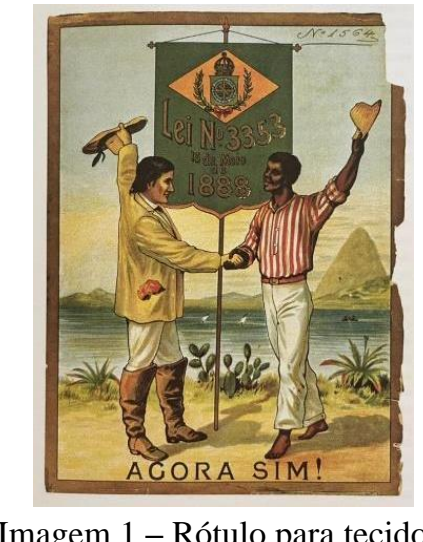

Imagem 1 - Rótulo para tecidos

Fonte: Rezende (2021, p. 37)

Dessa forma, estas pesquisadoras nos provocam a questionar: como nós, designers em formação na atualidade, poderíamos representar, em um projeto gráfico, o pelourinho no museu brasileiro? Há uma abordagem teórico metodológica no campo do design que nos permita escapar da superficialidade e hipocrisia para falar de nossa cultura escravocrata no contexto do Brasil atual? A teoria crítica do design, atravessada por estudos de decolonialidade e design ativismo, apresenta algumas alternativas de análise para responder a estas questões.

Luciana Ballestrin, ressalta a necessidade de compreendermos a "estrutura opressora do tripé colonialidade do poder, saber e ser como forma de denunciar e atualizar a continuidade da colonização e do imperialismo, mesmo findados os marcos históricos de ambos os processos" (BALLESTRIN, 2013. p. 11). A autora observa que a ideia de raça e, portanto, de racismo se tornaram categorias mentais da modernidade, quando a classificação e a hierarquização racial/étnica foram tornadas instrumentos da administração colonial e do padrão mundial de poder capitalista.

Elisabete Maria de Albuquerque (2018), com a pesquisa intitulada Design Gráfico em tempos de ativismo, ressalta que "a observação de uma imagem frequentemente mobiliza outros elementos como sentidos, percepções e pensamentos, que não estão presentes na imagem".

A imagem de um pelourinho traz à memória a dor e o sofrimento de pessoas que foram sequestradas de seus territórios originais para a submissão ao trabalho escravo, com a adoção desse instrumento de violência física e psicológica, útil à opressão daqueles que tentavam reagir e lutar pela sobrevivência com dignidade. Pelourinhos - enquanto ferramentas da colonialidade para controlar e punir quem ousasse defender a própria vida - simbolizam a negação do direito a existir como sujeito em sociedade, com uma identidade cultural. Tal como nos lembra Michael Pollak (1989), as memórias que envergonham, indizíveis, inconfessáveis, estão guardadas nas estruturas de comunicação dos não-ditos da memória coletiva nacional, e este é o caso de um pelourinho. 


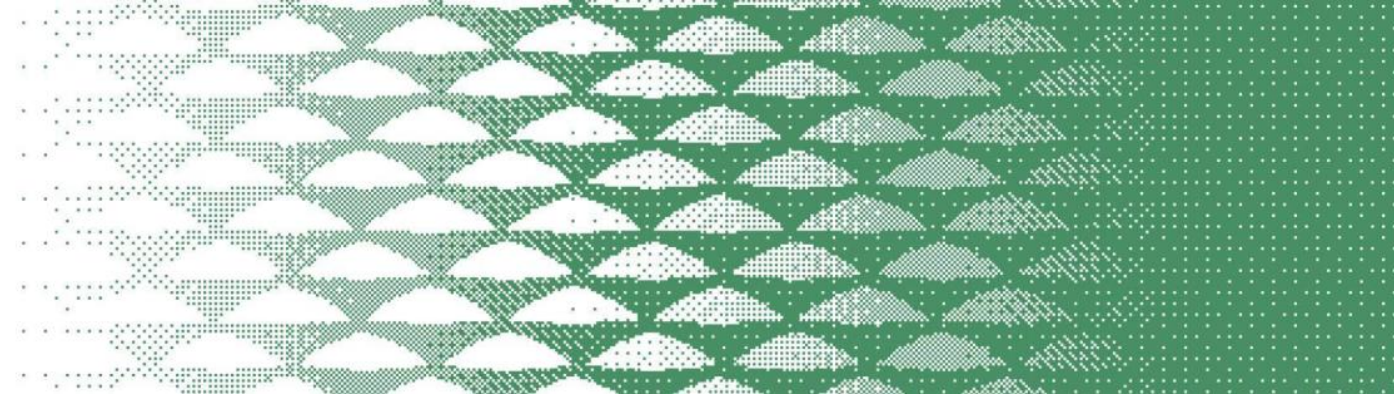

A questão que emergiu como um desafio à construção de um projeto gráfico digital em diálogo com a narrativa afirmada pelo Museu Cafua das Mercês foi: como, então, seria possível a um museu do negro apresentar o Pelourinho de São Luís como parte de seu acervo, de modo a fortalecer seu objetivo de promover sentimento de pertencimento e valorização da identidade cultural dos povos escravizados?

Como um ponto de partida para uma resposta, Grosfoguel e Bernardino-Costa (2016, p. 21) defendem que projetos político-acadêmicos da decolonialidade têm como centro "o reconhecimento de múltiplas e heterogêneas diferenças coloniais, assim como as múltiplas e heterogêneas reações das populações e dos sujeitos subalternizados à colonialidade do poder. A dominação colonial seria, portanto, o conector entre diversos lugares epistêmicos".

Em consonância, Myriam Sepúlveda dos Santos (2012), ao falar sobre a criação de Museus Afrodigitais, ressalta que o objetivo primordial desses espaços virtuais é promover o questionamento e a superação de classificações e hierarquias constituídas em teorias raciais que historicamente atravessam o imaginário popular nacional. Santos denuncia que a representação da escravidão nos museus brasileiros, em sua maioria financiados por instâncias governamentais, não raro esteriotipavam escravizados em condição humilhante, ao lado de objetos de tortura, sem apresentar os responsáveis pela escravização.

A partir da década de 1970, com o fortalecimento de movimentos sociais de trabalhadores e o surgimento do Movimento Negro unificado, começou a ser problematizada a ideologia de que o Brasil é um país que valoriza a mestiçagem. Caminhando nesse sentido, a Constituição de 1988 possibilitou a criação e avanço de políticas culturais que atendessem às demandas de movimentos identitários, o que foi incorporado por diversos museus, antigos e novos, como reforça a autora. Santos (2012) aponta, ainda, como os museus digitais têm contribuído, mais recentemente, para a crítica e modificação de narrativas que enaltecem os heróis escravagistas do colonialismo, ao promoverem espaços de interação e articulação a setores da população que tradicionalmente foram silenciados por discursos oficiais.

James Clifford, ao refletir sobre o conceito de museu como zona de contato, cunhado inicialmente por Mary Louise Pratt no livro Imperial Eyes: Travel and Transculturation, defende as dimensões interativas desses espaços, observando que "quando os museus são vistos como zonas de contato, sua estrutura organizacional enquanto coleção se torna uma relação atual, política e moral concreta - um conjunto de trocas carregadas de poder, com pressões e concessões de lado a lado." (CLIFFORD, 2016. p.5)

Essa é a abordagem teórica que orientou, portanto, nossas reflexões e escolhas para a elaboração do projeto gráfico, no sentido de apresentar o Pelourinho do Museu Cafua das Mercês como um objeto de um museu de contato, através do qual é possível encarar a história do Brasil colônia com o alinhamento a uma narrativa que considere as formas como, no presente, ainda somos marcados pelo passado escravocrata, evocando as histórias de luta dos povos escravizados. Dessa forma, tentamos "escovar a história a contrapelo".

\section{Metodologia}

Conforme definição de Gustavo Amarante Bomfim (1998), este estudo se caracterizou qualitativo, com uma abordagem descritiva, que para além das imagens, também se apresenta na forma dos textos que acompanham as imagens do projeto gráfico, bem como no texto deste artigo.

A primeira etapa metodológica implicou revisão da literatura, com textos debatidos em seminários durante a disciplina Projeto Gráfico I, na qual o projeto foi realizado. Enquanto a literatura de base se voltou às temáticas da decolonialidade e do design e ativismo, a literatura específica se 


\section{JOP 21 DESIGN
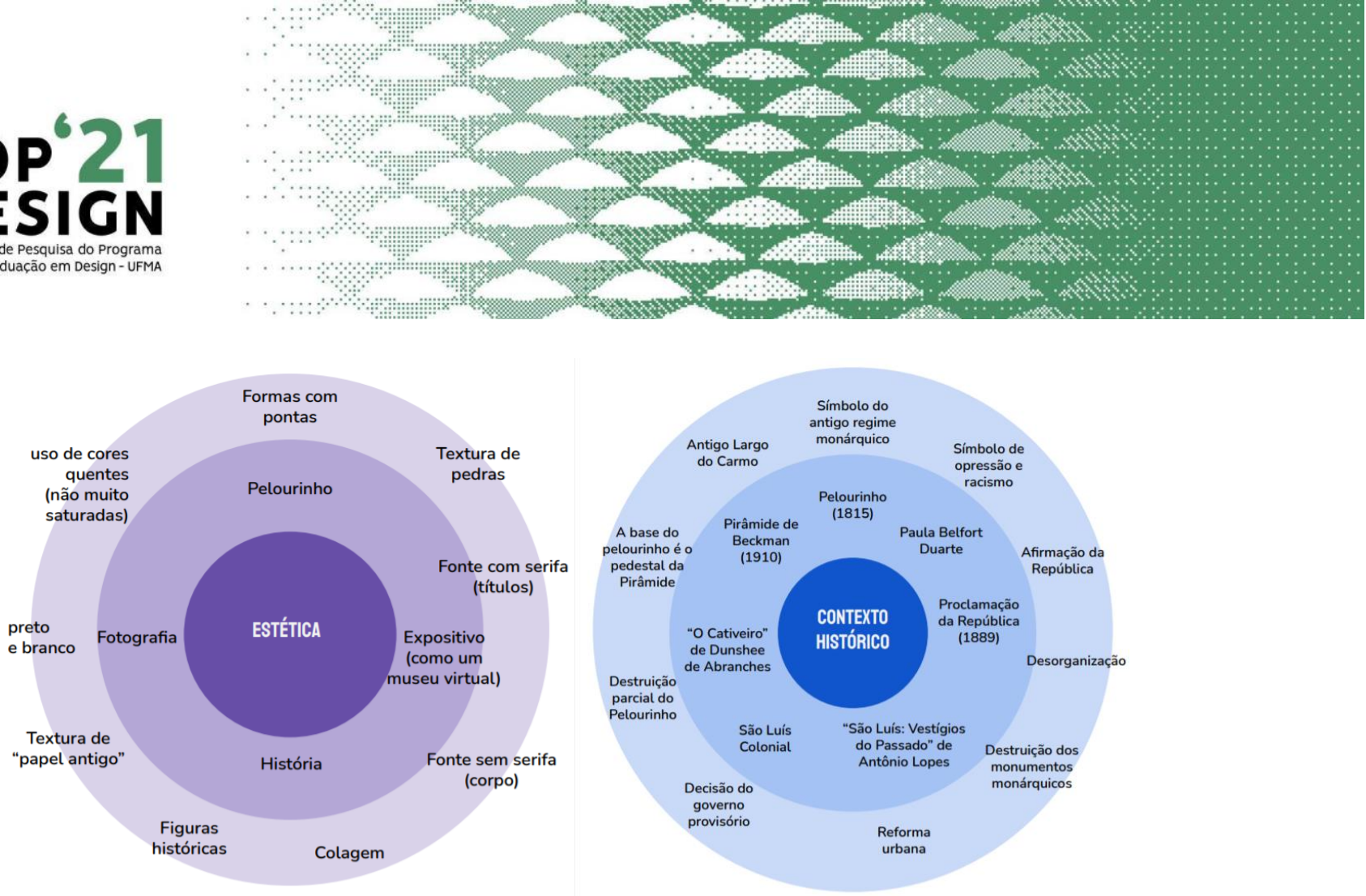

Imagens 2 e 3

Fonte: dos autores

No Moodboard, foram destacadas referências de design ativismo em redes sociais e do levantamento bibliográfico.

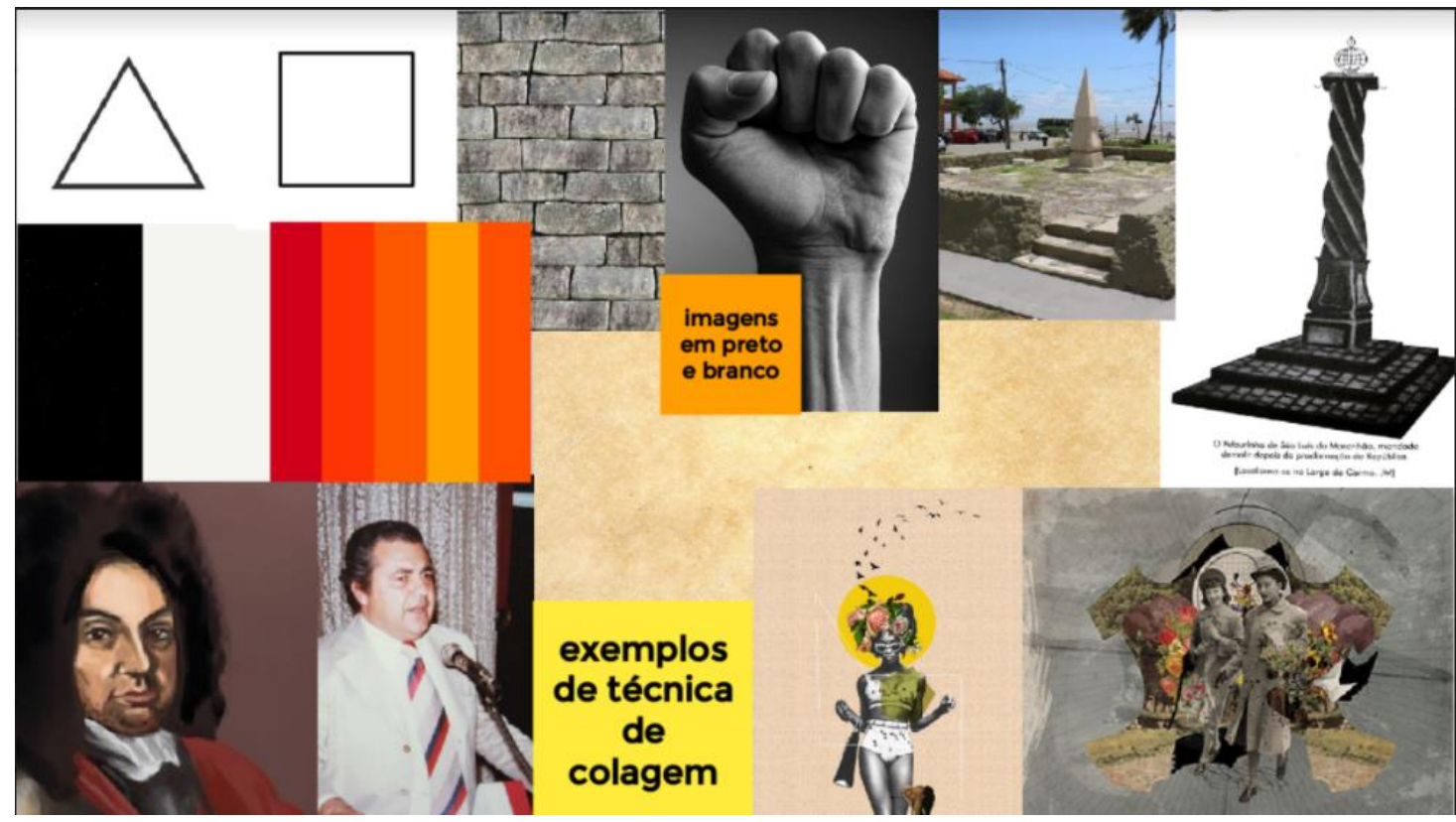

Imagem 4

Fonte: dos autores

Ao elaborar o esboço do layout dos posts a serem expostos via Instagram, foram observados a disposição de imagens de textos de modo a garantir boa legibilidade tanto em telas de computadores quanto em celulares.

Através do Storyboard, foram definidos detalhadamente as imagens e os elementos textuais do projeto gráfico, de modo a afirmar a narrativa histórica selecionada nas etapas anteriores 


\section{JOP 61 DESIGN
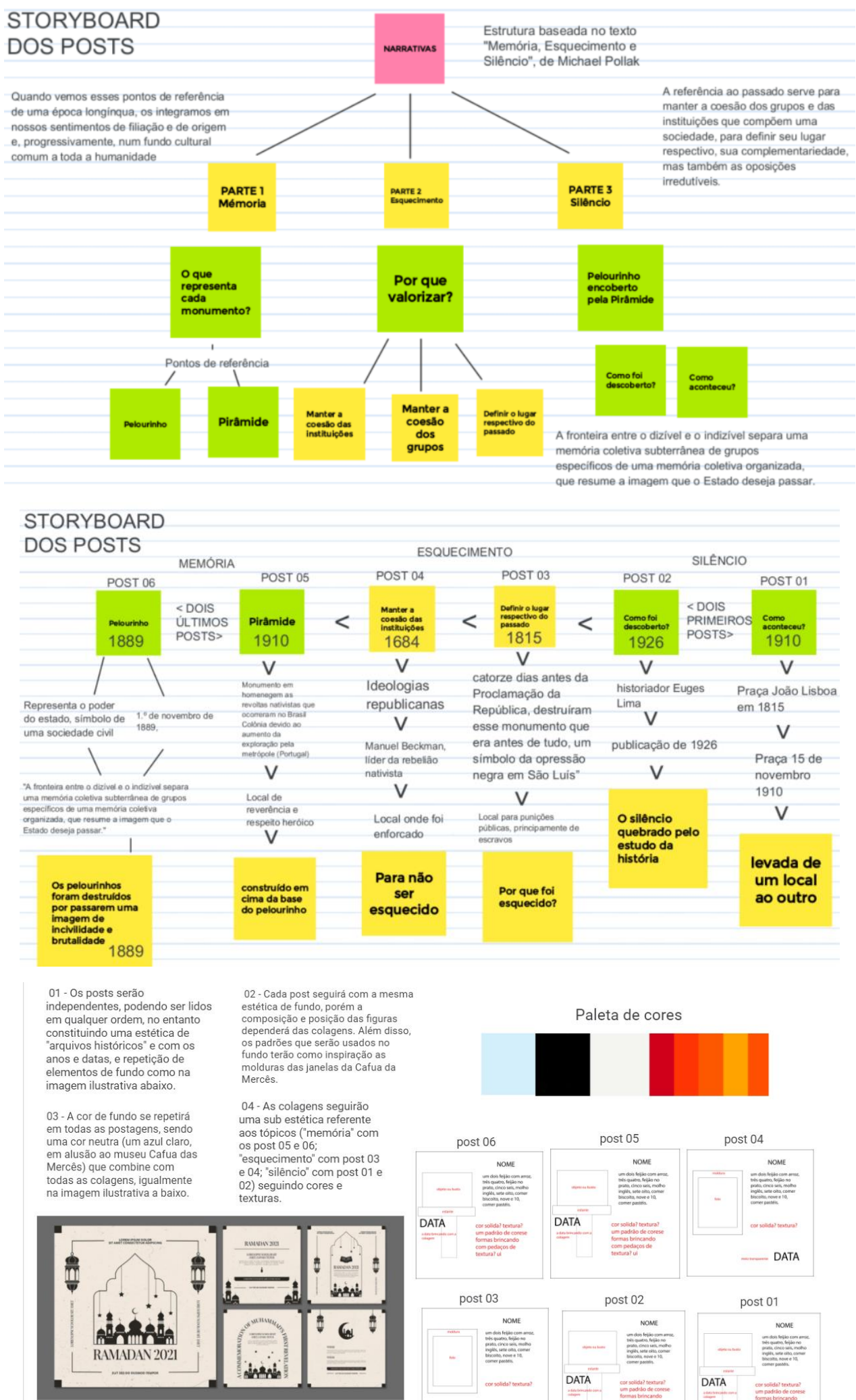

02 - Cada post seguirá com a mesma
estética de fundo, porém a

composição e posiçẵo das figuras

os padrões que serẫo usados no

molduras das janelas da Cafua da

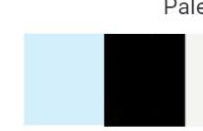

Paleta de cores

04 - As colagens seguirão

aos tópicos ("memória" com

os post 05 e 06;
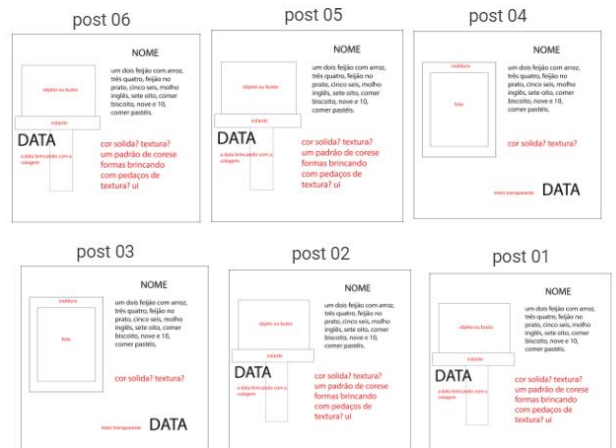

Imagem ilustrativa

Imagens 5, 6 e 7

Fonte: dos autores 


\section{JOP

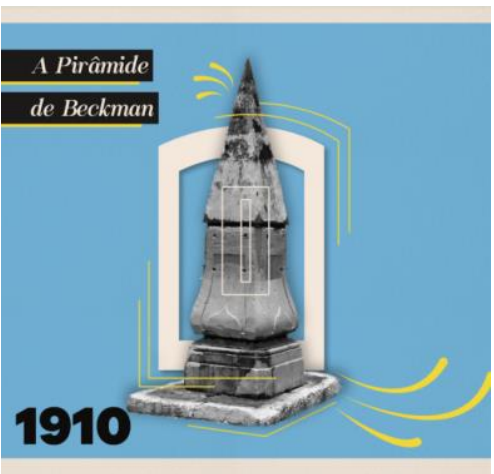

Imagem 13: Post 6

Fonte: dos autores

\section{Considerações finais}

Este estudo possibilitou aprendizagens sobre processos de construção de narrativas históricas, pautadas por reflexões nos campos da decolonialidade e do design ativismo. Assim, foi possível elaborar um projeto de design gráfico que apresente, pelo Instagram, o Pelourinho do Museu Cafua das Mercês enquanto um objeto histórico de um museu de contato, como explica Clifford (2016), ou seja, um espaço que promove diálogo crítico e respeitoso, aberto à diversidade tanto de histórias locais, quanto de perspectivas epistêmicas e de contextos em que são encenados os projetos de resistência ao sistema de poder colonial, conforme ensinam Bernardino-Costa e Grosfoguel (2016).

A tarefa de projetar no universo do design gráfico, sob essa perspectiva, traz dificuldades àqueles que ainda desejam uma metodologia limitada ao fazer epistemológico da modernidade, com métodos e técnicas de pesquisa que colocam o pesquisador na zona segura da imparcialidade científica. Transcender os limites de métodos e técnicas consagrados pela modernidade, amplamente difundidos pela ciência eurocêntrica, implica transitar por conceitos e teorias do pós-modernismo, do póscolonialismo, para, então, alcançar uma melhor compreensão do decolonialidade e do design ativismo enquanto ferramentas epistemológicas que permitem construção de narrativas críticas sobre a história dos povos colonizados.

Contudo, as dificuldades enfrentadas se tornam oportunidades para novas aprendizagens. Este estudo deixou claro que todo projeto gráfico reflete a leitura de mundo que um designer consegue realizar em seu tempo histórico.

\section{Pillory in São Luís: a narrative through design and activism about collective memory at the Cafua das Mercês museum}

Abstract: This article presents the process of creating a graphic project associated with a narrative about Pelourinho, a heritage collection on display at the Cafua das Mercês Museum, in the city of São Luís. Inspired by experiences and reflections related to Afrodigital Museums in Brazil, Design graduates from the Federal University of Maranhão followed the methodological steps guided by the discipline Graphic Design I: bibliographic review and group study of theoretical references related to the construction of ethnic narratives in museum exhibitions; listen interactive with the technical team of Cafua das Mercês to get to know the narrative adopted by this museum; in addition to experimenting with didactic and creative techniques such as mind map, moodboard and storyboard for 


\section{JOP \\ DESIGN \\ de Pós-Graduaçąo em Design - UFMA}

the elaboration of graphic pieces aligned with the concept of museum as a contact zone, described by James Clifford (2016).

Keywords: Museum; graphic design; pillory.

\section{Referências bibliográficas}

ABRANCHES, Dunshee de. 0 Cativeiro. 3 ed. São Luís, Edições AML, 2012.

ALBUQUERQUE, Elisabete Maria de. Design gráfico em tempos de ativismo. Repositório Digital da UFPE, 2018. Disponível em: https://repositorio.ufpe.br/handle/123456789/34595. Acesso em: $15 / 04 / 2021$

BALLESTRIN, Luciana. América Latina e o giro decolonial. Revista Brasileira de Ciência Política. N.11. Brasília, 2013.

BERNARDINO-COSTA, Joaze; GROSFOGUEL, Ramón. Decolonialidade e a perspectiva negra. Revista Sociedade e Estado - Volume 31 Número 1 Janeiro/Abril 2016.

BOMFIM, Gustavo A. Ideias e Formas na História do Design: Uma Investigação estética. 1. ed. João Pessoa: Editora Universitária da UFPB, 1998. v. 1. 184p.

BUZAN, Tony. Mapas mentais. Tradução de Paulo Polzonoff Jr. Rio de Janeiro: Sextante, 2009.

CLIFFORD, James. Museus como zonas de contato. Tradução de Alexandre Barbosa de Souza e Valquíria Prates. n.6. 2016.

FISCHER, Gustavo, SCALETSKY, Celso Carnos, AMARAL, Laura Guidali. O storyboard como instrumento de projeto: reencontrando as contribuições do audiovisual e da publicidade e seus contextos de uso no design. V.3 № 2, Unisinos. Strategic Design Research Journal, 3(2): 54-68, 2010. Acesso em $18 / 04 / 2021$.

GARRETTO, Gairo. Garrett: traficante de escravos. 1 ed. Rio de Janeiro: Editora Jaguatirica, 2018.

MARQUES, Walter, ROCHA, Viviane M., DINIZ, Maria de J. dos S., MONTEIRO, Thainara C. Arteeducação informal no Cafua das Mercês. Braz. J. of Develop., Curitiba, v. 6, n. 9, p. 64470-64480, sep. 2020.

MUSEU HISTÓRICO E ARTÍSTICO-MA. Cafua das Mercês. São Luís. 9 jul. 2020. Instagram: @museuhistoricoeartistico. Disponível

em

https://www.instagram.com/tv/CCcGEMPIgQG/?igshid=fz2mxnwts24z. Acesso em: 05/04/2021.

MUSEU HISTÓRICO E ARTÍSTICO-MA. Pelourinho de São Luís. São Luís. 9 jul. 2020. Instagram: @museuhistoricoeartistico. Disponível

em https://www.instagram.com/tv/CCcGEMPIgQG/?igshid=fz2mxnwts24z. Acesso em: 05/04/2021.

NORONHA, Raquel Gomes. 0 designer e a produção de sentido na construção de iconografias. In: A imagem na idade média: mediações na imagem e o popular contemporâneo / Marcus Ramúsyo de Almeida Brasil (org.); Raquel Gomes Noronha... [et al.]. - São Luís: EDUFMA, 2010.

PEREIRA, Taís Vieira; SCALETSKY, Celso Carnos. Mood Board Como Espaço de Construção de Metáforas e Conceitos de Design. IN: CIPED 2011, Lisboa: CIAUD, 2011.

POLLAK, Michael. Memória, Esquecimento, Silêncio. Tradução de Dora Rocha Flaksman. Estudos Históricos. Rio de Janeiro, vol 2. n. 3, 1989, p. 3-15. 
REZENDE, Lívia Lazzaro. A circulação de imagens no Brasil oitocentista: uma história com marca registrada. In: O design brasileiro antes do design: aspectos da história gráfica, 1870-1960 / Rafael Cardoso (org.); Lívia Lazzaro Rezende [et al.]. - 2 ed. São Paulo: Cosac Naify, 2011.

SANTOS, Myrian Sepúlveda dos. Museu Afrodigital: políticas culturais, identidade afrobrasileira e novas tecnologias. In: Museus afrodigitais e política patrimonial. São Luís: EDUFMA, p. 21-48, 2012. 